\title{
Capecitabine-induced hypertriglyceridemia: a rare but clinically relevant treatment-related adverse event
}

\author{
An Uche ${ }^{1}$, Ritika Vankina ${ }^{1}$, Jun Gong ${ }^{1,2}$, May Cho ${ }^{3}$, James J. Yeh ${ }^{1,4}$, Phyllis Kim ${ }^{1,4}$, Kathy Pan ${ }^{1,4}$ \\ ${ }^{1}$ Division of Medical Oncology and Hematology, Department of Medicine, Harbor-UCLA Medical Center, Torrance, CA, USA; ${ }^{2}$ Division of \\ Hematology/Oncology, Department of Medicine, Cedars-Sinai Medical Center, Los Angeles, CA, USA; ${ }^{3}$ Division of Hematology and Oncology, \\ Department of Internal Medicine, UC Davis Comprehensive Cancer Center, Sacramento, CA, USA; ${ }^{4}$ Los Angeles Biomedical Research Institute at \\ Harbor-UCLA Medical Center, Torrance, CA, USA \\ Correspondence to: Kathy Pan, MD. Los Angeles Biomedical Research Institute at Harbor-UCLA Medical Center, 1000 W Carson Street, Bldg N16, \\ Torrance, CA 90509, USA. Email: kathy.pan@labiomed.org.
}

\begin{abstract}
Capecitabine-induced hypertriglyceridemia (CIHT) represents an increasingly significant treatment-related adverse event from capecitabine given its potential for both acute complications (acute pancreatitis) and chronic metabolic complications (cardiovascular disease). The incidence of CIHT is relatively rare and the majority of cases thus far reported have been managed with lipid-lowering therapy and/or discontinuation of capecitabine followed by resumption of the drug upon normalization of triglyceride levels. We present among the first U.S. cases of CIHT to be reported in the published literature and highlight management approaches for this rare but clinically relevant adverse event. Further understanding of the mechanisms of CIHT and its long-term adverse effects as well as effective preventive strategies, interventions, and monitoring strategies are prudent given the widespread and often prolonged use of capecitabine-based chemotherapy in gastrointestinal and other cancers.
\end{abstract}

Keywords: Capecitabine; hypertriglyceridemia; adverse event (AE); colorectal cancer; breast cancer

Submitted Jun 06, 2018. Accepted for publication Jul 12, 2018.

doi: 10.21037/jgo.2018.07.07

View this article at: http://dx.doi.org/10.21037/jgo.2018.07.07

\section{Introduction}

Capecitabine $\left(\mathrm{XELODA}^{\circledR}\right)$ is an oral prodrug of $5^{\prime}$-deoxy5 -fluorouridine that is converted to 5 -fluorouracil (5-FU) in vivo. It was originally approved by the U.S. Food and Drug Administration (FDA) on April 30, 1998 as monotherapy for metastatic breast cancer (MBC) resistant to both paclitaxel- and anthracycline-based chemotherapy (1). Since then, capecitabine has received additional indications as monotherapy in metastatic colorectal cancer (mCRC), adjuvant colon cancer, and in combination with docetaxel in $\mathrm{MBC}$ (2). The most frequently reported grade $\geq 3$ treatment-related adverse events (AEs) of capecitabine in $\geq 1 \%$ of patients include diarrhea, hand-foot syndrome, hyperbilirubinemia, and lymphopenia (2). The incidence of capecitabine-induced hypertriglyceridemia (CIHT) is much rarer, while acute pancreatitis, the most feared complication of hypertriglyceridemia (HT), more likely occurs when serum triglyceride levels exceed $1,000 \mathrm{mg} / \mathrm{dL}$ (3). As patients are often treated with capecitabine for extended periods, chronic HT may increase the risk for cardiovascular disease (4). Management strategies for CIHT are unclear but needed. In this report, we present a case series of mCRC patients with CIHT and our management approaches to this rare but clinically relevant $\mathrm{AE}$.

\section{Case presentation}

\section{Case 1}

A 54-year-old male with recurrent and metastatic rectal adenocarcinoma to the bilateral lungs was treated with firstline capecitabine $\left[850 \mathrm{mg} / \mathrm{m}^{2}\right.$ twice daily (BID) for 14 days every 21 days], oxaliplatin $\left[130 \mathrm{mg} / \mathrm{m}^{2}\right.$ intravenous (IV over 2 hours on day 1 every 3 weeks)], and bevacizumab (7.5 mg/kg IV on day 1 every 3 weeks). He had previously 
been treated with six months of perioperative therapy comprised of neoadjuvant chemoradiation with capecitabine $\left(825 \mathrm{mg} / \mathrm{m}^{2}\right.$ BID on days of radiation) and adjuvant capecitabine and oxaliplatin (XELOX) for locally advanced disease. The patient was transitioned to capecitabine and bevacizumab after five cycles of XELOX-bevacizumab due to neuropathy. Before cycle 6 , the patient was found to have a triglyceride level of $3,783 \mathrm{mg} / \mathrm{dL}$ and chemotherapy was held for this asymptomatic, grade 4 HT. Fifteen days later, the triglyceride level decreased to $259 \mathrm{mg} / \mathrm{dL}$, and capecitabine and bevacizumab was resumed. After cycle 10 , triglyceride level rose to $2,765 \mathrm{mg} / \mathrm{dL}$ prompting withholding of capecitabine for one week, and the subsequent repeat level was $822 \mathrm{mg} / \mathrm{dL}$. The patient was prescribed fenofibrate $145 \mathrm{mg}$ daily and resumed capecitabine. His subsequent triglyceride levels have remained between 187-279 mg/dL (grade 1) on monthly laboratory monitoring.

\section{Case 2}

A 71-year-old man with history of type 2 diabetes mellitus who was diagnosed with mCRC to the liver was treated with single-agent capecitabine $\left(1,000 \mathrm{mg} / \mathrm{m}^{2}\right.$ BID for 14 days every 21 days). After cycle 3, a computed tomography (CT) scan of the chest, abdomen, and pelvis was obtained due to rising carcinoembryonic antigen (CEA) levels; this showed progression of disease (PD) with liver metastases. Therapy was changed to capecitabine $\left(850 \mathrm{mg} / \mathrm{m}^{2}\right.$ BID for 14 days every 21 days), oxaliplatin, and bevacizumab. A lipid panel obtained prior to initiation of XELOX-bevacizumab revealed a triglyceride level of $164 \mathrm{mg} / \mathrm{dL}$. After 3 cycles of XELOX-bevacizumab ( 6 cycles total of capecitabine), a repeat lipid panel was obtained and showed a triglyceride level of $866 \mathrm{mg} / \mathrm{dL}$. Chemotherapy was held and patient began gemfibrozil $600 \mathrm{mg}$ daily. Serial lipid panels obtained 1 and 2 weeks after showed triglyceride levels of $580 \mathrm{mg} / \mathrm{dL}$ and $214 \mathrm{mg} / \mathrm{dL}$, respectively. The patient was asymptomatic during this entire period of grade 3 CIHT. He subsequently resumed XELOX-bevacizumab and remains on gemfibrozil $600 \mathrm{mg}$ daily with triglyceride levels that are currently nearnormal on monthly monitoring.

\section{Case 3}

A 57-year-old man with recurrent, mCRC to the liver was treated with 6 cycles of XELOX-bevacizumab (capecitabine $850 \mathrm{mg} / \mathrm{m}^{2}$ BID for 14 days every 21 days) followed by maintenance single-agent capecitabine for nearly 3 years when repeat imaging showed complete response with resolution of liver lesions. Patient subsequently elected for a chemotherapy holiday. Two years later, he developed a local recurrence on surveillance colonoscopy and underwent surgery with a permanent colostomy followed by adjuvant chemoradiation with capecitabine. Four years later, he developed unresectable pulmonary metastases for which he resumed single-agent capecitabine $850 \mathrm{mg} / \mathrm{m}^{2}$ BID for 14 days every 21 days. After 2 cycles, the patient developed grade 2 HT (triglyceride level of $442 \mathrm{mg} / \mathrm{dL}$ ). Capecitabine was held and patient began gemfibrozil $600 \mathrm{mg}$ daily. His triglyceride levels peaked at $448 \mathrm{mg} / \mathrm{dL}$. Three months after holding capecitabine and initiating fibrate therapy, this decreased to $225 \mathrm{mg} / \mathrm{dL}$. The patient resumed capecitabine, and he is continuing chemotherapy with gemfibrozil with stable triglyceride levels in the mid-200s.

\section{Discussion}

The incidence of treatment-related grade 3-4 HT has been reported to be $0.1-0.2 \%$ in the U.S. FDA package inserts for capecitabine as monotherapy or as part of combination therapy $(1,2)$. The relative rarity of CIHT has often resulted in the lack of reporting for this $\mathrm{AE}$ in large phase III trials (5). To the best of our knowledge, we are presenting the first U.S. cases of CIHT described in the published literature. There are increasing cases of grade $\geq 3$ CIHT being reported elsewhere around the world (Table 1) in patients treated for MBC and mCRC with $(6,8,9,11-15)$ and without preexisting obesity, hyperlipidemia, or diabetes $(6,7,10,14,16,17)$. In many cases, CIHT is accompanied by mixed disturbances of the metabolic profile including: increased very-lowdensity lipoprotein (VLDL), increased total cholesterol (TC), increased or decreased low-density lipoprotein (LDL), increased or decreased high-density lipoprotein (HDL), increased blood glucose or glycated hemoglobin (HbA1c), or increased lipemic index, when compared to baseline (6-9,11-14,17). The dose-dependency of CIHT remains unclear as it has been shown to develop across a range of capecitabine doses, as monotherapy or as part of combination regimens, and as early as after 2 cycles or as delayed as 12 cycles of therapy (Table 1).

Larger clinical studies outside of the U.S. have provided further understanding that CIHT represents an AE that may not be as rare as once thought (Table 2). For example, one retrospective study reported an incidence of CIHT 
Table 1 Available case reports/series of capecitabine-induced hypertriglyceridemia (grade $\geq 3$ )

\begin{tabular}{|c|c|c|c|c|c|}
\hline $\begin{array}{l}\text { Country/ } \\
\text { location (n) }\end{array}$ & Dose/regimen & Baseline-peak & Treatment & Symptoms, post-tx levels, continued C? & Ref. \\
\hline \multirow[t]{4}{*}{ Greece [2] } & $\begin{array}{l}1,000 \mathrm{mg} / \mathrm{m}^{2} \text { BID } \times 14 \mathrm{~d} \\
\mathrm{Q} 21 \mathrm{~d}+\text { trastuzumab } \\
6 \mathrm{mg} / \mathrm{kg} \text { Q21d }\end{array}$ & $\begin{array}{l}\text { TG } 219 \rightarrow 1,409 \mathrm{mg} / \mathrm{dL} \\
\text { (after } 7 \text { cycles) }\end{array}$ & $\begin{array}{l}\text { Hold C, simvastatin } \\
20 \mathrm{mg} / \mathrm{d} \text {, omega-3 } \\
3 \mathrm{~g} / \mathrm{d}\end{array}$ & $\begin{array}{l}\text { None, TG } 129 \mathrm{mg} / \mathrm{dL} \text { after } 1 \text {-month } \\
\text { LLT, yes }\end{array}$ & (6) \\
\hline & $\begin{array}{l}1,000 \mathrm{mg} / \mathrm{m}^{2} \text { BID } \times 14 \mathrm{~d} \\
\text { Q21d + oxaliplatin } \\
130 \mathrm{mg} / \mathrm{m}^{2} \mathrm{Q} 21 \mathrm{~d}\end{array}$ & TC $239 \rightarrow 363 \mathrm{mg} / \mathrm{dL}$ & $\begin{array}{l}\text { Hold C, atorvastatin } \\
20 \mathrm{mg} / \mathrm{dc}\end{array}$ & $\begin{array}{l}\text { None, TG } 320 \mathrm{mg} / \mathrm{dL} \text { after } 2 \text { months } \\
\text { LLT, yes }\end{array}$ & \\
\hline & & $\begin{array}{l}\text { TG } 101 \rightarrow 1,510 \mathrm{mg} / \mathrm{dL} \\
\text { (after } 2 \text { cycles) }\end{array}$ & & & \\
\hline & & TC $203 \rightarrow 310 \mathrm{mg} / \mathrm{dL}$ & & & \\
\hline Turkey [2] & $\begin{array}{l}1,250 \mathrm{mg} / \mathrm{m}^{2} \mathrm{BID} \times 14 \mathrm{~d} \\
\text { Q21d }\end{array}$ & $\begin{array}{l}\text { TG } 324 \rightarrow 1,782 \mathrm{mg} / \mathrm{dL} \\
\text { (after } 7 \text { cycles) }\end{array}$ & $\begin{array}{l}\text { Hold C, atorvastatin } \\
20 \mathrm{mg} / \mathrm{d}\end{array}$ & $\begin{array}{l}\text { None, TG } 118 \mathrm{mg} / \mathrm{dL} \text { after } 8 \text { weeks } \\
\text { LLT, no due to PD }\end{array}$ & (7) \\
\hline Israel [1] & $\begin{array}{l}2,500 \mathrm{mg} / \mathrm{m}^{2} \mathrm{BID} \times 14 \mathrm{~d} \\
\text { Q21d }\end{array}$ & $\begin{array}{l}\text { TG } 337 \rightarrow 3,090 \mathrm{mg} / \mathrm{dL} \\
\text { (after } 2 \text { cycles) } \\
\text { TC } 212 \rightarrow 691 \mathrm{mg} / \mathrm{dL}\end{array}$ & $\begin{array}{l}\text { Hold C, bezafibrate } \\
\text { increased from } 400 \text { to } \\
800 \mathrm{mg} / \mathrm{d} \text {, atorvastatin } \\
20 \mathrm{mg} / \mathrm{d}\end{array}$ & $\begin{array}{l}\text { None, TG } 298 \mathrm{mg} / \mathrm{dL} \text { and TC } \\
310 \mathrm{mg} / \mathrm{dL} \text { after } 2 \text { weeks LLT, yes with } \\
\text { DR } 25 \% \text { but after cycle } 3 \text { discontinued } \\
\text { due to grade } 3 \mathrm{HT}\end{array}$ & (8) \\
\hline $\begin{array}{l}\text { United } \\
\text { Kingdom [1] }\end{array}$ & Monotherapy, dose NR & $\begin{array}{l}\text { TG } 5.3 \mathrm{mmol} / \mathrm{L} \rightarrow \\
41 \mathrm{mmol} / \mathrm{L} \\
\text { TC } 5.4 \rightarrow 11.6 \mathrm{mmol} / \mathrm{L} \\
\text { HbA1C } 5.9 \rightarrow 9.7 \% \\
\text { (after } 6 \text { cycles) }\end{array}$ & $\begin{array}{l}\text { Hold C, fenofibrate } \\
160 \mathrm{mg} / \mathrm{d} \text {, metformin }\end{array}$ & $\begin{array}{l}\text { Polydipsia, polyuria, and weakness, TG } \\
2.36 \mathrm{mmol} / \mathrm{L} \text { and TC } 3.5 \mathrm{mmol} / \mathrm{L} \text { after } \\
\text { 1-week LLT, HbA1C } 6.4 \% \text { after } \\
6 \text { months metformin }\end{array}$ & (9) \\
\hline \multirow[t]{2}{*}{ France [1] } & $\begin{array}{l}\text { Dose NR + } \\
\text { bevacizumab (dose NR) }\end{array}$ & $\begin{array}{l}\text { TG } 2.51 \rightarrow 26.77 \mathrm{mmol} / \mathrm{L} \\
\text { (after } 6 \text { cycles) }\end{array}$ & Fenofibrate (dose NR) & $\begin{array}{l}\text { None, TG } 6.26 \mathrm{mmol} / \mathrm{L} \text { after } 1 \text {-week } \\
\text { LLT, no due to PD }\end{array}$ & (12) \\
\hline & & TC $6.68 \rightarrow 8.75 \mathrm{mmol} / \mathrm{L}$ & & & \\
\hline $\begin{array}{l}\text { Hong } \\
\text { Kong [1] }\end{array}$ & $\begin{array}{l}1,500 \mathrm{mg} / \mathrm{m}^{2} \mathrm{BID} \times 14 \mathrm{~d} \\
\text { Q21d }\end{array}$ & $\begin{array}{l}\text { No baseline } \mathrm{TG} \rightarrow \\
111.2 \mathrm{mmol} / \mathrm{L} \\
\text { (after } 5 \text { cycles) }\end{array}$ & $\begin{array}{l}\text { Hold C, gemfibrozil } \\
(\text { dose NR), } \\
\text { plasmapheresis } \times 2\end{array}$ & $\begin{array}{l}\text { Pancreatitis and septic shock, } \\
\text { lipemic index normalized after } \\
\text { plasmapheresis, TG normal } 2 \text { months } \\
\text { after discontinuation of LLT, no }\end{array}$ & (13) \\
\hline \multirow[t]{2}{*}{ Turkey [2] } & $\begin{array}{l}1,000 \mathrm{mg} / \mathrm{m}^{2} \mathrm{BID} \times 14 \mathrm{~d} \\
\text { Q21d }\end{array}$ & $\begin{array}{l}\text { TG } 270 \rightarrow 9,063 \mathrm{mg} / \mathrm{dL} \\
\text { (after } 5 \text { cycles) }\end{array}$ & $\begin{array}{l}\text { Lipid pheresis, } \\
\text { gemfibrozil (dose NR) }\end{array}$ & None, 207 mg/dL after LLT, no & (14) \\
\hline & $\begin{array}{l}1,000 \mathrm{mg} / \mathrm{m}^{2} \mathrm{BID} \times 14 \mathrm{~d} \\
\text { Q21d }\end{array}$ & $\begin{array}{l}\text { TG } 251 \rightarrow 657 \mathrm{mg} / \mathrm{dL} \\
\text { (after } 8 \text { cycles) }\end{array}$ & LLT (agent and dose NR) & $\begin{array}{l}\text { None, } 202 \mathrm{mg} / \mathrm{dL} \text { after LLT, NR if C } \\
\text { resumed }\end{array}$ & \\
\hline $\begin{array}{l}\text { Netherlands } \\
\text { [1] }\end{array}$ & $\begin{array}{l}\text { Dose NR + oxaliplatin } \\
\text { (dose NR) }\end{array}$ & $\begin{array}{l}\text { No baseline TG } \rightarrow 138 \\
\mathrm{mmol} / \mathrm{L} \text { (after } 3 \text { cycles) }\end{array}$ & $\begin{array}{l}\text { Hold C, gemfibrozil } \\
\text { (dose NR) }\end{array}$ & None, TG normalized but details NR & (15) \\
\hline
\end{tabular}

Table 1 (continued) 
Table 1 (continued)

\begin{tabular}{|c|c|c|c|c|c|}
\hline $\begin{array}{l}\text { Country/ } \\
\text { location (n) }\end{array}$ & Dose/regimen & Baseline-peak & Treatment & Symptoms, post-tx levels, continued C? & Ref. \\
\hline Lebanon [1] & $\begin{array}{l}1,250 \mathrm{mg} / \mathrm{m}^{2} \mathrm{BID} \times 14 \mathrm{~d} \\
\text { Q21d }\end{array}$ & $\begin{array}{l}\text { No baseline TG } \rightarrow \\
2,322 \mathrm{mg} / \mathrm{dL} \\
\text { (after } 9 \text { months therapy) }\end{array}$ & Fenofibrate 200 mg/d & $\begin{array}{l}\text { None, TG } 312 \text { mg/dL after 1-month } \\
\text { LLT, yes }\end{array}$ & (16) \\
\hline \multirow[t]{3}{*}{ China [2] } & $\begin{array}{l}1,000 \mathrm{mg} / \mathrm{m}^{2} \text { BID } \times 14 \mathrm{~d} \\
\text { Q21d + oxaliplatin } \\
130 \mathrm{mg} / \mathrm{m}^{2} \text { Q21d }\end{array}$ & $\begin{array}{l}\text { Normal baseline TG } \rightarrow \\
2.47 \mathrm{mmol} / \mathrm{L} \\
\text { (after } 2 \text { cycles) }\end{array}$ & Hold C & $\begin{array}{l}\text { None, } 1.45 \mathrm{mmol} / \mathrm{L} 2 \text { months after } \\
\text { discontinuation, no }\end{array}$ & (17) \\
\hline & $\begin{array}{l}1,000 \mathrm{mg} / \mathrm{m}^{2} \text { BID } \times 14 \mathrm{~d} \\
\mathrm{Q} 21 \mathrm{~d}+\text { oxaliplatin } \\
130 \mathrm{mg} / \mathrm{m}^{2} \mathrm{Q} 21 \mathrm{~d}\end{array}$ & $\begin{array}{l}\text { Normal baseline } \\
\mathrm{TC} \rightarrow 6.93 \mathrm{mmol} / \mathrm{L}\end{array}$ & $\begin{array}{l}\text { DR C } 25 \% \text {, hold } \\
\text { oxaliplatin }\end{array}$ & $\begin{array}{l}\text { None, TG normalized within } \\
2 \text { months dose modification, yes }\end{array}$ & \\
\hline & & $\begin{array}{l}\text { Normal baseline } \\
\mathrm{TG} \rightarrow 2.41 \mathrm{mmol} / \mathrm{L} \\
\text { (after } 6 \text { cycles) }\end{array}$ & & & \\
\hline
\end{tabular}

C, capecitabine; BID, twice daily; TG, triglycerides; TC, total cholesterol; LLT, lipid-lowering therapy; PD, progressive disease; DR, dose-reduced; NR, not reported; HbA1c, hemoglobin A1c; tx, treatment.

as high as $10 \%$ in treated patients, while another reported an incidence of grade $\geq 3$ CIHT in $4 \%(20,22)$. Median triglyceride levels and average TC levels have been shown to increase over time in capecitabine-treated patients, and more so in those with preexisting diabetes or lipid disorders (23). In patients treated with capecitabine as monotherapy or as part of combination therapy, the median time to development of grade $\geq 2$ CIHT was 79 days (range, 16-243 days) (22). Reassuringly, the overwhelming majority of CIHT cases are asymptomatic with only a few cases resulting in clinically significant manifestations such as acute pancreatitis (Tables 1,2).

The mechanisms by which CIHT develops remain unclear. Several reports have postulated that HT is induced by capecitabine itself or its generated metabolites prior to formation of 5 -fluorouracil by thymidine phosphorylase $(8,18,19,22,23)$. Enzymatic interference by capecitabine of lipid metabolism pathways involving lipoprotein lipase (LPL), hepatic triglyceride lipase, and apoproteins has also been described as a potential mechanism of HT, suggesting that CIHT may be more prevalent in individuals with susceptible genetic polymorphisms resulting in differential drug metabolism or hereditary defects in lipid metabolism such as inherited LPL deficiency $(6-8,11,18,22,23)$. Impaired activity of LPL results in accumulation of chylomicrons and VLDL, whereas statins activate LPL and increase clearance of such triglyceride-rich lipoproteins, providing a basis for the often rapid and significant responses of CIHT to statin therapy $(6,22)$. Notably, a LPL defect can also occur with increases in its inhibitor, apolipoprotein CIII, and/or decreases in its activator, apolipoprotein CII, although the relationship between capecitabine and apolipoprotein CII/CIII levels has yet to be formally explored $(12,22,23)$. In one report of CIHT, tests for apolipoprotein B and LPL activity were normal while genetic disorders of lipid metabolism including apolipoprotein CII deficiency and familial dysbetalipoproteinemia (apolipoprotein E genotype was E3/E3) were excluded during the work-up (15).

The FDA package insert for capecitabine does not provide specific dosing and management guidelines for CIHT. In general, for grade 2 treatment-related AEs it is recommended to hold the drug until resolution of the AE to grade $0-1$ and resume the drug at $100 \%$ of the starting dose (for first occurrences), $25-50 \%$ of the starting dose (for second and third occurrences), or discontinue the drug (for the fourth occurrence) $(1,2)$. For grade 3 AEs, it is also recommended to hold capecitabine until resolution of the $\mathrm{AE}$ to grade $0-1$ and resume at $75 \%$ (if first occurrence) or $50 \%$ of the starting dose (if second occurrence); if a grade $3 \mathrm{AE}$ occurs for the third time, it is recommended to discontinue capecitabine. For grade 4 $\mathrm{AEs}$, it is recommended to discontinue or hold capecitabine until resolution of the AE to grade $0-1$ followed by a dose reduction to $50 \%$ of the starting dose. 


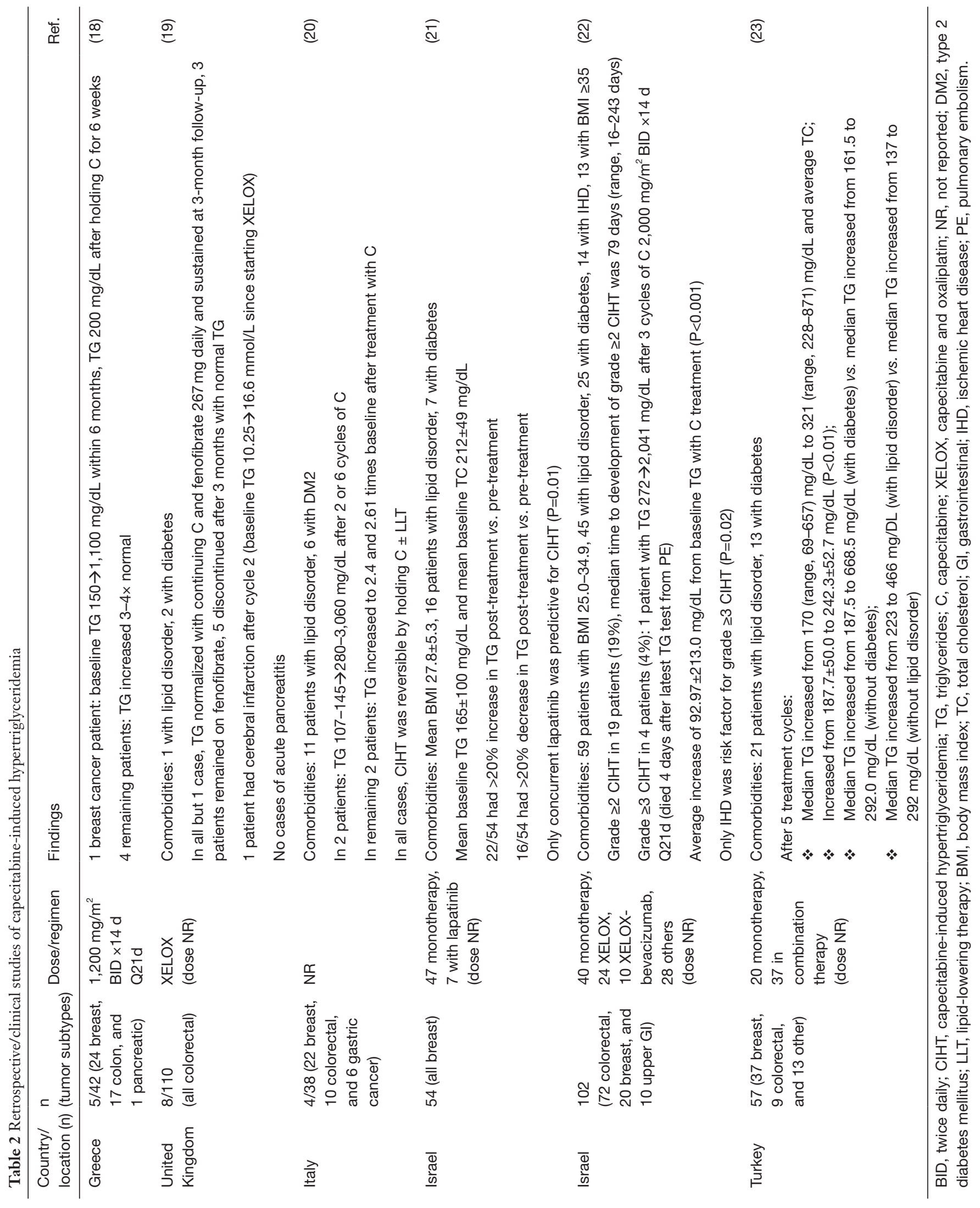


Discontinuation of capecitabine results in reduction of triglyceride levels, although increases in triglycerides after resumption of capecitabine have been observed (7). Aside from holding capecitabine and awaiting normalization of triglycerides prior to restarting the drug as recommended by the FDA dosing guidelines, a growing body of evidence supports that dietary modification and addition of lipidlowering therapy are effective in mitigating CIHT and allowing timely resumption of capecitabine (Tables 1,2). Fibrates are often the preferred first-line treatment in patients with severe HT (24). Omega-3 fatty acids and niacin are also useful agents in HT, whereas statins at high doses exhibit significant hypotriglyceridemic activity.

Indeed, a recent prospective United Kingdom study on CIHT implemented a protocol when CIHT was detected; this entailed referral to the general practitioner (or metabolic disease team for severe HT) and initiation of first-line fenofibrate $267 \mathrm{mg}$ daily for triglyceride levels $>5 \mathrm{mmol} / \mathrm{L}$ while continuing capecitabine (19). This important study demonstrated the feasibility of treating CIHT while continuing capecitabine without any significant clinical consequences detected.

Notably, other reports have shown that when capecitabine is not withheld, resistance of HT to lipidlowering therapy may develop (10). In patients with preexisting hyperlipidemia, resistance to lipid-lowering therapy has similarly been observed (8). In mild cases of CIHT, dose reduction of capecitabine without lipidlowering therapy may be sufficient enough to reverse CIHT (17). In resistant cases of CIHT, increasing the fibrate dose and/or addition of a statin may be needed to resolve the $\mathrm{AE}$ (8). At our institution, we have favored the practice of holding capecitabine and initiating fibrate therapy for grade $\geq 2$ CIHT, which has resulted in normalization of HT in our series of patients and allowed timely and safe resumption of an important chemotherapeutic agent in the treatment paradigm of our cancer patients.

We are in agreement with the recommendations of several groups for the regular monitoring of lipid profiles in patients treated with capecitabine, particularly in those with risk factors for cardiovascular disease, including dyslipidemia, diabetes, hypertension, obesity, and coronary heart disease $(8,11,12,18,20-23)$. Others groups have mandated checking of a lipid panel before initiation of capecitabine or other 5 -fluorouracil prodrugs (12). Importantly, preexisting lipid disorder and diabetes mellitus have increasingly been shown to be risk factors for development of clinically significant $\mathrm{HT}$ from capecitabine $(21,23)$. In patients at risk, it is reasonable to perform a baseline lipid survey prior to initiation of capecitabine therapy or at the least by cycle 2 or 3 of capecitabine to allow early intervention $(19,22)$. In the United Kingdom, one protocol necessitated fasting serum lipids prechemotherapy, at cycle 3 or 4 of capecitabine, and before the final cycle with initiation of lipid-lowering therapy and healthcare referrals when CIHT was detected (19). Persistently abnormal levels were monitored for up to 3 months after chemotherapy, or more often as indicated, and fenofibrate was discontinued 3 months after the end of chemotherapy if HT normalized with further repeat lipid profiling 3 months after discontinuation of fenofibrate. It is worthwhile to mention that the authors concluded that continuous routine lipid screening of all patients on capecitabine-containing chemotherapy is not justified, and an agreed upon management plan between physician and patient should be reached when CIHT is detected.

In conclusion, CIHT is an increasingly recognized treatment-related $\mathrm{AE}$ of capecitabine with potentially significant acute and chronic metabolic complications. Most cases of CIHT are asymptomatic and can be resolved with lipid-lowering therapy and/or holding of the drug with resumption following improvement in triglyceride levels. Given the widespread and more prolonged use of capecitabine-containing chemotherapy across a spectrum of cancers, further understanding of the mechanisms of CIHT, its long-term effects on outcome, preventative strategies, effective interventions, monitoring practices are warranted.

\section{Acknowledgements}

None.

\section{Footnote}

Conflicts of Interest: The authors have no conflicts of interest to declare.

Informed Consent: Written informed consent was obtained from the patients for publication of this case report and any accompanying images.

\section{References}

1. U.S. Food \& Drug Administration. Drugs@FDA: FDA Approved Drug Products. [Accessed November 20, 
2017]. Available online: https://www.accessdata.fda.gov/ drugsatfda_docs/label/2000/20896lbl.pdf

2. U.S. Food \& Drug Administration. Drugs@FDA: FDA Approved Drug Products. Accessed November 20, 2017. Available online: https://www.accessdata.fda.gov/ drugsatfda_docs/label/2016/020896s039lbl.pdf

3. Scherer J, Singh VP, Pitchumoni CS, et al. Issues in hypertriglyceridemic pancreatitis: an update. J Clin Gastroenterol 2014;48:195-203.

4. Talayero BG, Sacks FM. The role of triglycerides in atherosclerosis. Curr Cardiol Rep 2011;13:544-52.

5. Cassidy J, Clarke S, Díaz-Rubio E, et al. Randomized phase III study of capecitabine plus oxaliplatin compared with fluorouracil/folinic acid plus oxaliplatin as first-line therapy for metastatic colorectal cancer. J Clin Oncol 2008;26:2006-12.

6. Koutras AK, Habeos IG, Vagenakis AG, et al. Capecitabine-induced hypertriglyceridemia: a report of two cases. Anticancer Res 2006;26:2249-51.

7. Kurt M, Babaoglu MO, Yasar U, et al. Capecitabineinduced severe hypertriglyceridemia: Report of two cases. Ann Pharmacother 2006;40:328-31.

8. Bar-Sela G, Haim N. Uncontrolled hypertriglyceridemia induced by capecitabine: Case report and review of the literature. Cancer Chemother Pharmacol 2009;63:779-82.

9. Garg R, Angus E, Fincher S. Capecitabine-induced severe hypertriglyceridaemia and diabetes: A case report and review of the literature. Diabet Med 2009;26:1308-9.

10. Orphanos GS, Stavrou NG, Picolos MK. Hypertriglyceridemia: An underdiagnosed side effect of capecitabine chemotherapy. Acta Oncol 2010;49:262-3.

11. Yildiz B, Kavgaci H, Fidan E, et al. Oral fluoropyrimidineinduced severe hyperlipidemia. Asian Biomedicine 2010;4:627-30.

12. Javot L, Spaëth D, Scala-Bertola J, et al. Severe hypertriglyceridaemia during treatment with capecitabine. Br J Cancer 2011;104:1238-9.

13. Chan HY, Ng CM, Tiu SC, et al. Hypertriglyceridaemiainduced pancreatitis: A contributory role of capecitabine?

Cite this article as: Uche A, Vankina R, Gong J, Cho M, Yeh JJ, Kim P, Pan K. Capecitabine-induced hypertriglyceridemia: a rare but clinically relevant treatment-related adverse event. J Gastrointest Oncol 2018;9(6):1213-1219. doi: 10.21037/ jgo.2018.07.07
Hong Kong Med J 2012;18:526-9.

14. Duman BB, Paydas S, Tetiker T, et al. Capecitabineinduced hypertriglyceridemia and hyperglycemia: Two cases. Pharmacology 2012;90:212-5.

15. Polinder-Bos HA, Kok EE, van de Wiel A, et al. Severe hypertriglyceridaemia associated with the use of capecitabine. Neth J Med 2012;70:104.

16. Samer T, Joseph K. Capecitabine induced hypertriglyceridaemia: An underreported and potentially severe side effect. J Cancer Res Ther 2014;2:82-3.

17. Han GH, Huang JX. Hypertriglyceridemia and hyperglycemia induced by capecitabine: A report of two cases and review of the literature. J Oncol Pharm Pract 2015;21:380-3.

18. Stathopoulos GP, Koutantos J, Lazaki H, et al. Capecitabine (Xeloda) as monotherapy in advanced breast and colorectal cancer: Effectiveness and side-effects. Anticancer Res 2007;27:1653-6.

19. Michie CO, Sakala M, Rivans I, et al. The frequency and severity of capecitabine-induced hypertriglyceridaemia in routine clinical practice: A prospective study. Br J Cancer 2010;103:617-21.

20. Seminara P, Losanno T, Emiliani A, et al. Cancer chemotherapy and cardiovascular risks: Is capecitabineinduced hypertriglyceridemia a rare adverse effect? Cardiology 2010;116:42-4.

21. Geva S, Lazarev I, Geffen DB, et al. Hypertriglyceridemia in patients with metastatic breast cancer and treatment with capecitabine. J Chemother 2013;25:176-80.

22. Bar-Sela G, Cohensius-Kent D, Vornikova O, et al. Increase in triglyceride blood level in patients treated with capecitabine: A retrospective survey. Anticancer Drugs 2014;25:729-34.

23. Sürmelioğlu N, Paydaş S, Karataş Y, et al. Evaluation of lipid profiles in patients treated with capecitabine. Turk J Med Sci 2017;47:1206-9.

24. Filippatos TD, Elisaf MS. Recommendations for severe hypertriglyceridemia treatment, are there new strategies? Curr Vasc Pharmacol 2014;12:598-616. 